\title{
Silicon modulates multi-layered defense against powdery mildew in Arabidopsis
}

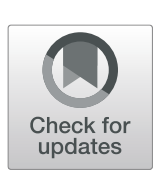

\author{
Lili Wang ${ }^{1,2}$, Min Dong ${ }^{1}$, Qiong Zhang ${ }^{2}$, Ying Wu ${ }^{2}$, Liang Hu², James F. Parson², Edward Eisenstein ${ }^{2,3}$, \\ Xiangge $\mathrm{Du}^{1 *}$ and Shunyuan Xiao ${ }^{2,4^{*}}$
}

\begin{abstract}
Silicon (Si) has been widely employed in agriculture to enhance resistance against pathogens in many crop plants. However, the underlying molecular mechanisms of Si-mediated resistance remain elusive. In this study, the Arabidopsispowdery mildew pathosystem was employed to investigate possible defense mechanisms of Si-mediated resistance. Because Arabidopsis lacks efficient Si transporters and thus is a low Si-accumulator, two heterologous Si influx transporters (from barley and muskmelon) were individually expressed in wild-type Arabidopsis Col-0 and a panel of mutants defective in different immune signaling pathways. Results from infection tests showed that while very low leaf Si content slightly induced salicylic acid (SA)-dependent resistance, high Si promoted PAD4-dependent but largely EDS1and SA-independent resistance against the adapted powdery mildew isolate Golovinomyces cichoracearum UCSC1. Intriguingly, our results also showed that high Si could largely reboot non-host resistance in an immune-compromised eds1/pad4/sid2 triple mutant background against a non-adapted powdery mildew isolate G. cichoracearum UMSG1. Taken together, our results suggest that assimilated Si modulates distinct, multi-layered defense mechanisms to enhance plant resistance against adapted and no-adapted powdery mildew pathogens, possibly via synergistic interaction with defense-induced callose.
\end{abstract}

Keywords: Silicon, Arabidopsis, Powdery mildew, PAD4, Salicylic acid, Disease resistance, Callose

\section{Background}

Silicon ( $\mathrm{Si})$ is the second most abundant element on the earth. Although it is not considered to be an essential element for plant growth, Si has long been recognized as a "beneficial" or "quasi-essential" substance to plants, mainly due to its important role in plant nutrition, particularly under stressful conditions. Over the past 25 years, a plethora of studies with $>800$ publications have collectively shown that $\mathrm{Si}$ can effectively protect plants from abiotic stresses, including drought, salinity and metals toxicity, as well as biotic stresses caused by insect herbivores or various pathogens ranging from viruses, bacteria, fungi, oomycetes, to nematodes (Van Bockhaven et al. 2012; Coskun et al.

\footnotetext{
* Correspondence: duxge@cau.edu.cn; xiao@umd.edu

'College of Plant Protection, China Agricultural University, Beijing 100193,

China

${ }^{2}$ Institute for Bioscience and Biotechnology Research, University of Maryland, Rockville, MD 20850, USA

Full list of author information is available at the end of the article
}

2019). However, despite the extensive studies, the exact molecular mechanisms underlying the protective roles of $\mathrm{Si}$ in plants still remain elusive (Coskun et al. 2019). Conceivably, this knowledge gap limits the exploitation of the full potential concerning practical application of $\mathrm{Si}$ in agriculture.

It has been demonstrated that $\mathrm{Si}$ needs to be absorbed by plants through passive channel-type, selective $\mathrm{Si}$ transporters to realize its prophylactic effect (Ma 2010). Intriguingly, $\mathrm{Si}$ accumulation varies over 100 -fold in different plant species, ranging from 0.1 to $10 \%$ in dry weight (Epstein 1994). Based on the levels of Si accumulation, plants are divided into three categories: high $\mathrm{Si}$ (or active) accumulator, intermediate $\mathrm{Si}$ (or passive) accumulator and low Si (rejective) accumulator (Takahashi et al. 1990). Understandably, most studies on Si transport and its physiological roles in plants have been conducted with high accumulators, and to a lesser extent,

(c) The Author(s). 2020 Open Access This article is licensed under a Creative Commons Attribution 4.0 International License, which permits use, sharing, adaptation, distribution and reproduction in any medium or format, as long as you give appropriate credit to the original author(s) and the source, provide a link to the Creative Commons licence, and indicate if changes were made. The images or other third party material in this article are included in the article's Creative Commons licence, unless indicated otherwise in a credit line to the material. If material is not included in the article's Creative Commons licence and your intended use is not permitted by statutory regulation or exceeds the permitted use, you will need to obtain permission directly from the copyright holder. To view a copy of this licence, visit http://creativecommons.org/licenses/by/4.0/. 
intermediate accumulators. The ability of a particular plant for the accumulation of $\mathrm{Si}$ is determined by the transport efficiency of its Si influx transporters. The first identified Si influx transporter (OsLsi1) in higher plants was found in rice in 2006 (Ma et al. 2006). Since then, many Si transporters homologous to OsLsi1 have been identified and characterized in different plant species, such as barley (HvLsi1) (Chiba et al. 2009), wheat (TaLsi1) (Montpetit et al. 2012), pumpkin (CmLsi1) (Mitani et al. 2011). By contrast, no similar Si transporter has been identified in Arabidopsis, agreeing with its classification as a low $\mathrm{Si}$ accumulator.

Mechanistic studies on how Si exerts a prophylactic effect on plants using high or intermediate $\mathrm{Si}$ accumulators have been focused on the aspect of disease resistance. Based on published data generated with distinct pathosystems, two types of mechanisms have been proposed to explain how $\mathrm{Si}$ might act in plant cells. The first type conforms to the "apoplastic obstruction hypothesis" recently proposed by Coskun and colleagues based on many observations that $\mathrm{Si}$ is deposited on the plant cell surface or in the apoplastic space whereby it strengthens physical barriers that can limit entry of pathogens and/or delivery of pathogen molecules (Coskun et al. 2019). For example, Si can accumulate and deposit beneath the cuticle of rice leaves to reduce penetration of rice blast Magnaporthe grisea (Yoshida 1965) and Si can also polymerize in specialized cells and cellular structures of some species (particularly grasses), such as leaf silica and long cells, and spikelet hairs and papillae to strengthen the physical barriers to prevent pathogen entry (Rafi et al. 1997). For the second type of mechanism, some studies have suggested that Si may be able to potentiate a plant defense program(s), which enables more sensitive and rapid response of plants to pathogen attack (Van Bockhaven et al. 2012). Inducible plant defense mechanisms have been extensively studied in the field of molecular plantmicrobe interaction and known to engage a conserved and complex network of signal transduction pathways that may involve activation of mitogen-activated protein kinases, and/or production and signaling of small-molecule phytohormones such as salicylic acid (SA), jasmonic acid (JA), and/or ethylene (ET) (Pieterse et al. 2009). If these molecular and biochemical events are "primed" to a more readystate by $\mathrm{Si}$, more effective chemical defense ensues. For example, $\mathrm{Si}$ application was reported to reprogram gene transcription in uninoculated rice plants (Van Bockhaven et al. 2012) and may modulate the rice ET pathway to induce resistance to the brown spot fungus Cochliobolus miyabeanus, which is a necrotrophic pathogen (Van Bockhaven et al. 2015). However, in many cases, Si supplementation had little, if any, effect on gene expression of plants (Fauteux et al. 2006; Brunings et al. 2009; Chain et al. 2009).

The role of $\mathrm{Si}$ in promoting disease resistance is particularly evident in the case of powdery mildew as shown in cucumber, muskmelon, and zucchini squash, barley, and rose (Menzies et al. 1992; Wiese et al. 2005; Shetty et al. 2012). In mechanistic studies concerning Si-mediated resistance to powdery mildew, $\mathrm{Si}$ has been shown to strengthen papilla-mediated inhibition of appressorial penetration in wheat (Bélanger et al. 2003), and it has also been reported to promote the accumulation of antifungal flavonoid phytoalexins in rose (Shetty et al. 2011). Thus, Si appears to promote both physical and chemical barriers against powdery mildew (and possibly other) pathogens. However, the genetic and molecular basis of Si's action largely remained unexplored until a recent genetic study in which transgenic Arabidopsis expressing a heterologous $\mathrm{Si}$ transporter was exploited to address this question. Vivancos et al. (2015) expressed the wheat Si transporter (TaLsi1) in Arabidopsis wild-type Col-0 and mutants that are defective in SA-signaling (due to the loss of PAD4) or biosynthesis (due to the loss of SID2). They showed that TaLsi1expressing Col-0 plants were able to accumulate high levels of $\mathrm{Si}$ and hence exhibited enhanced resistance to powdery mildew. Interestingly, they found that pad4 and sid 2 mutant plants transgenic for TaLsi1 also showed similar levels of resistance when $\mathrm{Si}$ was supplied. These results suggested that $\mathrm{Si}$, when above a threshold level, is able to activate disease resistance via an unknown mechanism(s) that is largely independent of SA signaling (Vivancos et al. 2015).

In this study, we employed the Arabidopsis-powdery mildew pathosystem to further investigate the molecular mechanisms of Si-mediated disease resistance in plants. Our results present genetic evidence for the role of $\mathrm{Si}$ in multi-layered plant defense mechanisms, which should help clarify the current confusion and controversy over the molecular mechanisms underlying Si's positive role in plant disease resistance against fungal pathogens.

\section{Results}

Plants with either very low or very high endogenous Si display enhanced resistance against powdery mildew In our pilot experiment, we surprisingly found that Arabidopsis thaliana wild-type Col-0 plants grown in regular soil matrix (Sun Gro Horticulture, Massachusetts) irrigated with deionized water without $\mathrm{Si}$ became slightly less susceptible to an adapted powdery mildew isolate Golovinomyces cichoracearum (Gc) UCSC1 compared to those grown in the same soil irrigated with $1.7 \mathrm{mM}$ silicon or with tap water (Additional file 1: Figure S1). Measurement of leaf Si content showed that plants irrigated with deionized water only had lower levels of Si than those irrigated with deionized water $+\mathrm{Si}$ or with tap water (which contains $\sim 8 \mathrm{mg} / \mathrm{L} \mathrm{Si}$, Additional file 1: Figure S2a), and there was no significant difference between the latter two (Additional file 1: Figure $S 2 b)$. These preliminary results suggested that leaf $\mathrm{Si}$ content below a certain threshold level may enhance basal resistance in Arabidopsis and that cautions are needed when selecting soil and water for Si-related 
experiments. Therefore, to reliably assess the role of $\mathrm{Si}$ in modulating plant defense mechanisms, we decided to use perlite which contains the least amount of Si available to plants compared to three other types soil media (Additional file 1: Figure S2c) to grow Arabidopsis plants for a more accurate supply of Si dissolved in deionized water in all of our later experiments. We first tested eight-week-old wild-type Col-0 plants with Gc UCSC1. As expected, we found that Col-0 plants irrigated with the nutrient solution without $\mathrm{Si}(-\mathrm{Si})$ showed enhanced disease resistance, which was discernable by the naked eye when compared with plants irrigated with the same nutrient solution plus $1.0 \mathrm{mM} \mathrm{Si}$ (+Si) (Fig. 1a). Quantification of fungal spore production at 10 days post-inoculation (dpi) showed that plants of Col- $0 /-\mathrm{Si}$ produced $\sim 30 \%$ fewer spores than plants of Col- $0 /+\mathrm{Si}$ (Fig. 1b). Leaf $\mathrm{Si}$ content in Col-0/-Si plants was $1.60 \mathrm{mg} / \mathrm{g}$ dry leaf tissue, whereas Col-0/+Si plants had slightly but significantly higher leaf Si content $(2.38 \mathrm{mg} / \mathrm{g} ; \sim 48 \%$ increase) (Fig. 1c). These results reinforce the notion that Arabidopsis was a low Siaccumulator with poor $\mathrm{Si}$ absorption (Vivancos et al. 2015) and suggest that very low endogenous Si may prime defense activation in Arabidopsis against powdery mildew pathogens.

In order to evaluate the impact of higher levels of assimilated $\mathrm{Si}$ in plant defense using Arabidopsis, we generated Col-0 lines expressing the barley (Hordeum vulgare) $\mathrm{Si}$ influx transporter-encoding gene HvLsi1 (Chiba et al. 2009) or the muskmelon (Cucumis melo) Si influx transporter-encoding gene CmeLsi1 (which was amplified from the genomic DNA of muskmelon based on sequence homology to the Cucurbita moschata Si influx transporter gene CmLsi1) (Mitani et al. 2011). As expected, all transgenic lines supplemented with $\mathrm{Si}$ showed high Si content. For example, CmeLsi1-expressing Col-0 plants of a representative T3 homozygous line treated with exogenous $\mathrm{Si}$ increased leaf Si content by $280 \%(5.52 \pm 0.43 \mathrm{mg} / \mathrm{g})$ compared with untreated control plants of the same transgenic line (Fig. 2a). Interestingly, HvLsi1, when expressed in Col-0, appeared to have a stronger $\mathrm{Si}$ absorbing capability than CmeLsi1, because leaf $\mathrm{Si}$ content in plants of one representative Col-0 transgenic line expressing HvLsi1 increased by $55 \%$ compared with untreated Col-0 even without
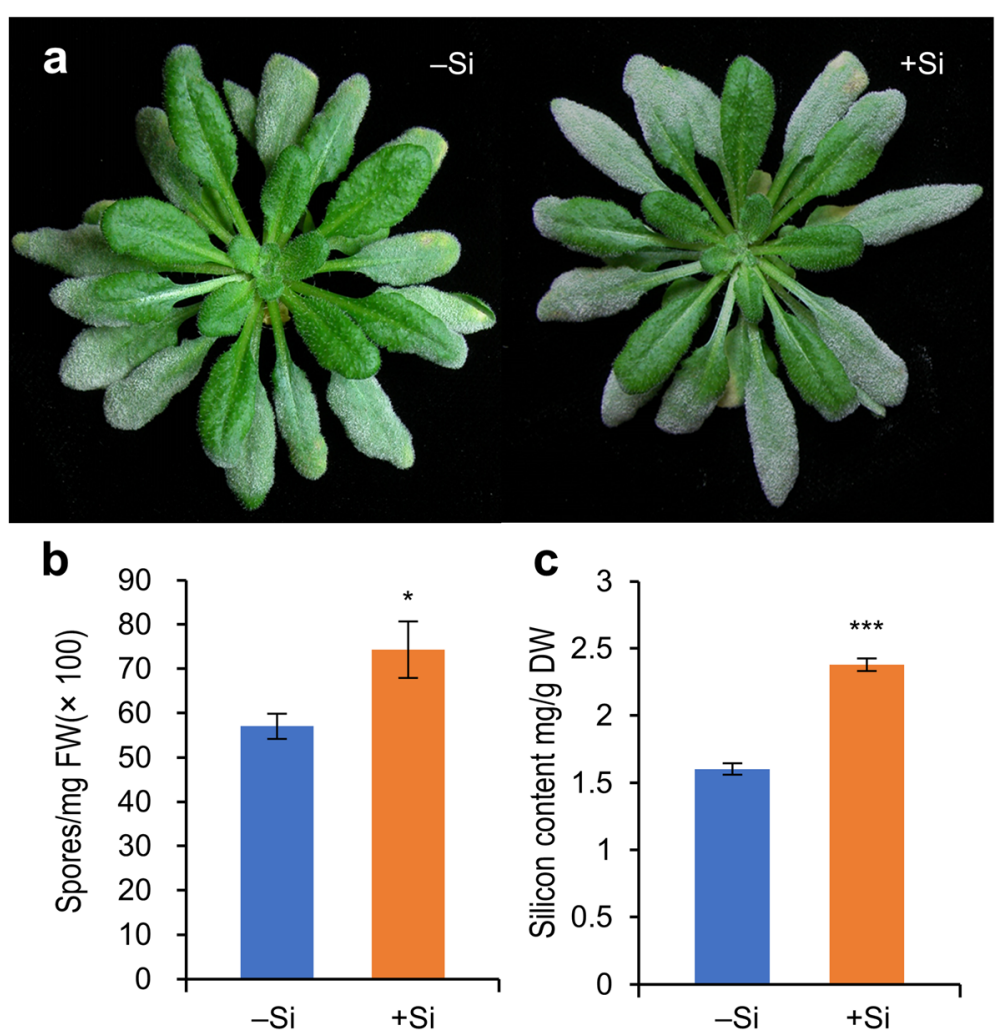

Fig. 1 Arabidopsis plants containing very low leaf Si exhibit enhanced basal resistance against an adapted powdery mildew pathogen. a Infection phenotypes of representative Arabidopsis Col-0 plants grown in perlite supplemented with 0 mM (-Si) or 1.0 mM (+Si) silicon (See Methods for details). Seven-week-old plants were inoculated with G. cichoracearum (GC) UCSC1. Photos were taken at 10 dpi. b Quantification of spore production in the infected leaves of the plants in (a) at 10 dpi. c Silicon content in leaves of Col-0 plants grown under conditions indicated in (a) before fungal infection. FW, fresh weight; DW, dry weight; Error bar indicates SE based on 4 replicates, and asterisks denote significant difference (Student $t$-test, ${ }^{*} P<0.05,{ }^{* * *} P<0.001$ ) 

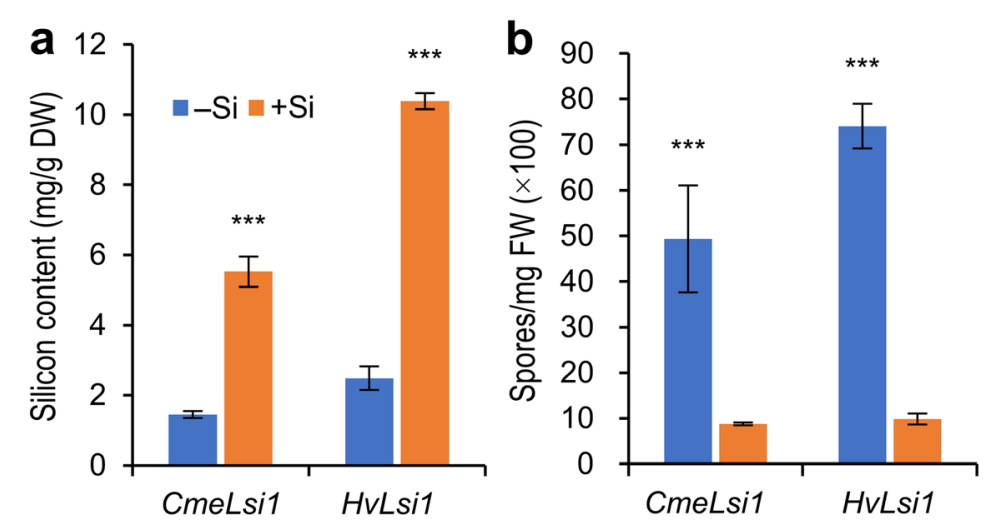

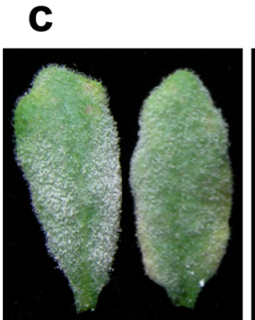

CmeLsi1-Si

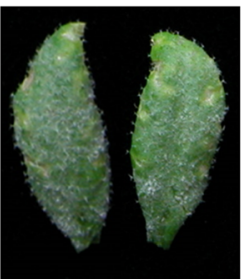

CmeLsi1 +Si

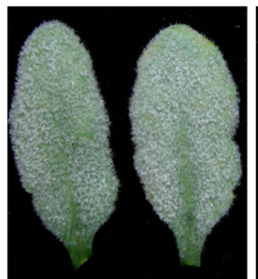

HVLsi1-Si

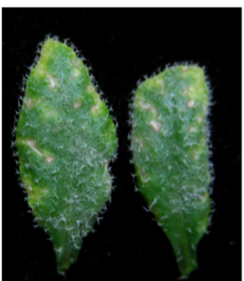

$H v L s i 1+\mathrm{Si}$

Fig. 2 Transgenic Arabidopsis plants with high leaf Si content display enhanced resistance against powdery mildew. a Silicon content in leaves of transgenic Arabidopsis CmLsi1/Col-0 or HvLsil/Col-0 plants grown in perlite supplemented with $0 \mathrm{mM}$ (-Si) or $1.0 \mathrm{mM}$ (+Si) silicon. b Quantification of spore production in the infected leaves of the plants in (a). c Representative GC UCSC1-infected leaves of the indicated transgenic Arabidopsis Col-0 plants. Pictures were taken at $10 \mathrm{dpi}$. Error bar indicates SE based on 4 replicates, and asterisks denote significant difference (Student $t$-test, ${ }^{* * *} P<0.001$ )

exogenous $\mathrm{Si}$ application and further increased by $318 \%(10.38 \pm 0.22 \mathrm{mg} / \mathrm{g})$ in plants supplied with $\mathrm{Si}$, resulting in $\mathrm{Si}$ accumulation of more than $1 \%$ of the total dry weight (Fig. 2a). Similar patterns were seen in other genetic backgrounds (Additional file 1: Figure S3).

We then tested plants of these transgenic lines grown in perlite supplied with $\mathrm{Si}(1.0 \mathrm{mM})$ or without $\mathrm{Si}$ with $G c$ UCSC1. Visual disease scoring and spore quantification showed that both HvLsi1- and CmeLsi1-transgenic plants with Si supplement displayed remarkable enhanced resistance in comparison with plants of the respective transgenic lines without Si supplement (Fig. 2c). Interestingly, HvLsi1-Col-0/-Si plants (with a leaf Si content of $2.49 \pm$ $0.34 \mathrm{mg} / \mathrm{g}$ ) showed a similar level of disease susceptibility as $\mathrm{Col}-\mathrm{O} /+\mathrm{Si}$ plants (with a similar leaf $\mathrm{Si}$ content of $2.38 \pm 0.05 \mathrm{mg} / \mathrm{g}$ ) (Fig. 1a and Fig. 2c), whereas CmeLsi1Col-0/-Si plants (with a leaf Si content of $1.45 \pm 0.10 \mathrm{mg} /$ g) showed reduced susceptibility similar to the level seen in Col-0/-Si plants (with a leaf Si content of $1.60 \pm 0.04$ $\mathrm{mg} / \mathrm{g}$ ) (Fig. 1a and Fig. 2c). Quantification of fungal spore production fully supported the visual phenotypes (Fig. 2b).

\section{Very low Si-conditioned resistance requires SA-pathway components EDS1, PAD4 and SID2}

$\mathrm{H}_{2} \mathrm{O}_{2}$ production and accumulation in mildew-invaded epidermal cells correlate with known powdery mildew resistance mechanisms in Arabidopsis (Xiao et al. 2003) and other plants (Wei et al. 1998). To understand why plants with very low $\mathrm{Si}$ content are more resistant to powdery mildew, we first performed DAB (3,3'-Diaminobenzidine) staining of infected leaves of Col-0 for in situ detection of $\mathrm{H}_{2} \mathrm{O}_{2}$ accumulation. We found that Col-0/-Si plants showed more frequent $\mathrm{H}_{2} \mathrm{O}_{2}$ accumulation in powdery mildew-invaded epidermal cells $(\sim 15 \%)$ in comparison with Col- $0 /+$ Si plants $(\sim 5 \%)$ (Fig. 3a), which likely contributed to the enhanced resistance in Col-0/-Si plants.

Next, to investigate the possible defense signaling pathway(s) engaged for the $\mathrm{H}_{2} \mathrm{O}_{2}$ production and resistance to powdery mildew due to very low $\mathrm{Si}$ content in Col-0/-Si plants, we prepared plants of eds1, pad4, sid2, coi1, ein2 single and eds1pad4 double, and eds1pad4sid2 triple Arabidopsis mutants that are defective in SA-dependent (EDS1, PAD4 and SID2), jasmonic acid (JA)-dependent (COI1) and ethylene-dependent (EIN2) signaling pathways in perlite supplemented with or without Si. Infection tests with Gc UCSC1 revealed that plants of coil/-Si and ein2/ -Si showed slightly enhanced resistance in comparison with their respective $+\mathrm{Si}$ plants, similar to the situation of Col-0/-Si vs. Col-0/+Si (Fig. 3b). By contrast, plants of the remaining genotypes that are defective in SA signaling or biosynthesis displayed no significant difference between $\mathrm{Si}$ and $+\mathrm{Si}$-treated plants (Fig. 3b). Quantification of fungal spore production supported the visual phenotypes (Fig. 3c). DAB staining showed that those mutants defective in 


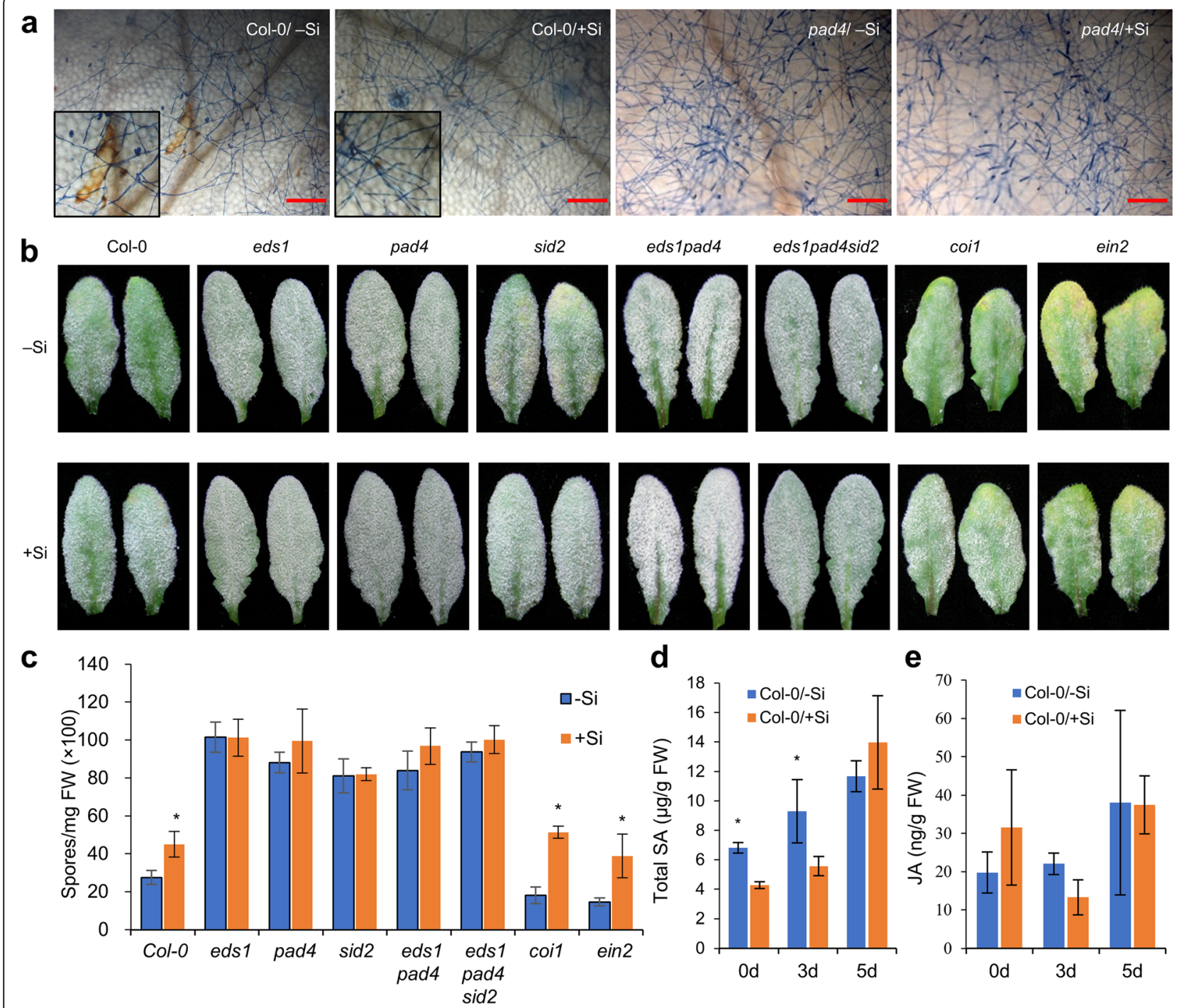

Fig. 3 Very low Si-conditioned powdery mildew resistance requires SA-pathway components EDS1, PAD4 and SID2. a Representative microscopic images showing growth of GC UCSC1 at 5 dpi on leaves of Col-0 or pad4-1 plants grown in perlite supplemented with 0 mM (-Si) or 1.0 mM (+Si) Si. Fungal structures were stained blue by trypan blue, while production and accumulation of $\mathrm{H}_{2} \mathrm{O}_{2}$ by the host was visualized as reddish-brown stain (highlighted in the insets) upon reaction with 3,3-diaminobenzidine. Scale bars $=200 \mu \mathrm{m}$. b Representative Gc UCSC1-infected leaves of plants from the indicated genotypes grown in perlite supplemented with $0 \mathrm{mM}(-\mathrm{Si})$ or $1.0 \mathrm{mM}(+\mathrm{Si})$ Si. Pictures were taken at 10 dpi. c Quantification of spore production at 10 dpi in plants of the indicated genotypes in (b). d, e Total SA and JA levels in GC UCSC1-infected leaves of wild-type Col-0 plants grown in perlite supplemented with $0 \mathrm{mM}(-\mathrm{Si})$ or $1.0 \mathrm{mM}$ (+Si) Si. Leaf samples were collected and analyzed at 0, 3 and 5 dpi. Error bar indicates SE based on 4 replicates, and asterisks denote significant difference (Student $t$-test, ${ }^{*} P<0.05$ )

SA-signaling or biosynthesis (as represented by pad4) showed no $\mathrm{H}_{2} \mathrm{O}_{2}$ accumulation in powdery mildewinvaded epidermal cells of either $-\mathrm{Si}$ or $+\mathrm{Si}$-treated plants (Fig. 3a).

To further determine if very low leaf Si content somehow constitutively activates an SA-dependent defense mechanism, we also measured leaf SA and JA levels of the Col-0 plants before and after infection. We found that Col-0/-Si plants indeed had slightly but significantly higher total SA levels at 0 and 3 dpi compared to Col-0/ $+\mathrm{Si}$ plants (Fig. 3d), whereas there was no significant difference in JA levels between Col-0/-Si and Col-0/+Si plants (Fig. 3e). Thus, together our data suggest that very low leaf Si content ectopically activates SA-dependent basal defense against powdery mildew.

High Si-conditioned resistance is largely SA-independent but PAD4-dependent

To investigate if high $\mathrm{Si}$-conditioned stronger resistance has the same or a distinct mechanistic basis, we first wondered if the enhanced resistance in transgenic plants of CmeLsi1Col- $0 /+\mathrm{Si}$ and $H v L s i 1-\mathrm{Col}-0 /+\mathrm{Si}$ is also associated with 
$\mathrm{H}_{2} \mathrm{O}_{2}$ production. DAB staining detected $\mathrm{H}_{2} \mathrm{O}_{2}$ production in sporadic mesophyll cells unrelated to fungal infection and occasionally in powdery mildew-infected epidermal cells of these plants (Fig. 4a, b). However, little $\mathrm{H}_{2} \mathrm{O}_{2}$ production was detectable in plants of the CmeLsi1 -Col-O/-Si and HvLsi1-Col-0/-Si lines and these plants supported larger and more advanced mycelial networks at $5 \mathrm{dpi}$ compared to their +Si-treated counterparts (Fig. 4c, d). These observations suggest that very high $\mathrm{Si}$ content may trigger $\mathrm{H}_{2} \mathrm{O}_{2}$ production in mesophyll cells and potentiate $\mathrm{H}_{2} \mathrm{O}_{2}$ production in powdery mildew-invaded epidermal cells.

Next, we introduced the same DNA constructs for expression of the two heterologous Si transporters into seven single Arabidopsis mutants (i.e. eds1, pad4, sid2, coi1, ein2), one double (eds1pad4) and one triple (eds1pad4sid2) mutant. Measurement of $\mathrm{Si}$ content showed that expression of HvLsi1 or CmeLSi1 resulted in elevation of leaf $\mathrm{Si}$ content in the backgrounds of all of these mutants (Additional file 1: Figure S3), similar to that in Col-0 (Fig. 2a), indicating that none of these immunity-related mutations interferes with $\mathrm{Si}$ uptake. We then grew plants of the above described representative transgenic lines under $-\mathrm{Si}$ or $+\mathrm{Si}$ conditions for seven weeks and then inoculated them with Gc UCSC1 and assessed their disease reaction phenotypes. As shown in Fig. 5a, b, all transgenic lines without Si supplement exhibited disease susceptibility phenotypes as expected based on their genotypes (i.e. those SApathway defective mutants were more susceptible than Col-0 and those defective in JA or ET pathways). Strikingly, for the transgenic plants supplemented with $\mathrm{Si}$, only plants of those genotypes that contain the pad4 mutation, i.e. pad4, eds1pad4 and eds1pad4sid2 did not show enhanced disease resistance relative to their counterparts without Si supplement (Fig. 5ad). These results indicate that high $\mathrm{Si}$ contentmediated resistance is EDS1-, SA- and JA/ET-independent but PAD4-dependent.

To evaluate the molecular attributes of the PAD4dependent mechanism activated by high Si content, we first used qRT-PCR to measure the expression levels of PR1 in plants of HvLsi1-Col-0 plants with or without $\mathrm{Si}$ treatment at 0, 3, 5 dpi with Gc UCSC1. We found that PR1 in HvLsi1-Col-0/+Si plants was highly expressed before powdery mildew infection (0 dpi) and had no or only slight increase at 3 or 5 dpi (Additional file 1: Figure S4). This observation is in agreement with $\mathrm{H}_{2} \mathrm{O}_{2}$ production independent of powdery mildew infection in HvLsi1-Col0/+Si plants (Fig. 4d). Next, we examined if high leaf Si content can increase PAD4 expression. Interestingly, we
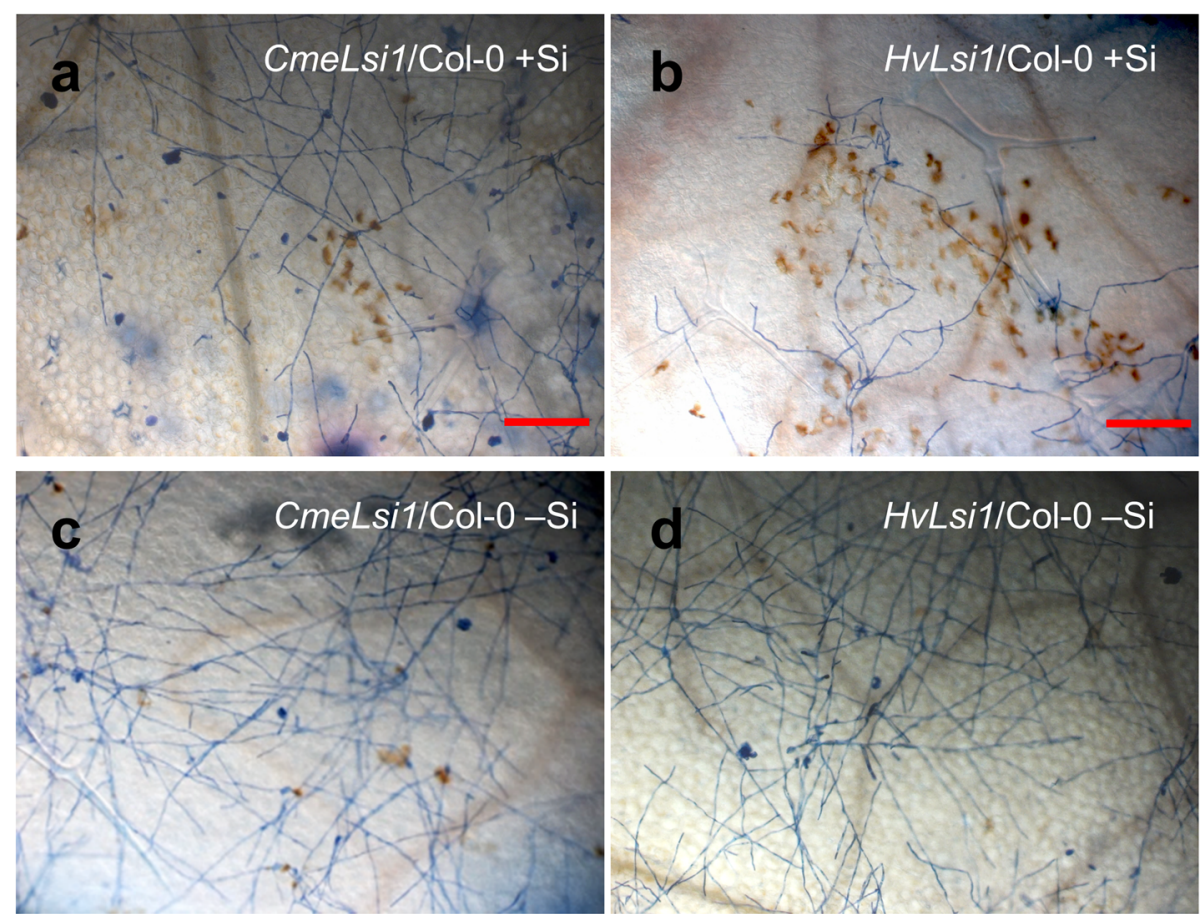

Fig. 4 High Si content enhances $\mathrm{H}_{2} \mathrm{O}_{2}$ production in leaves of Col-0 plants expressing a heterologous silicon transporter. a, b, c and $\mathbf{d}$ Representative microscopic images showing growth of GC UCSC1 at 5 dpi on leaves of the plants of the indicated genotypes grown in perlite supplemented with $0 \mathrm{mM}(-\mathrm{Si})$ or $1.0 \mathrm{mM}(+\mathrm{Si}) \mathrm{Si}$. Production and in situ accumulation of $\mathrm{H}_{2} \mathrm{O}_{2}$ was visualized as reddish-brown stain upon reaction with 3,3-diaminobenzidine, while fungal structures were stained blue by trypan blue. Scale bars $=200 \mu \mathrm{m}$ 


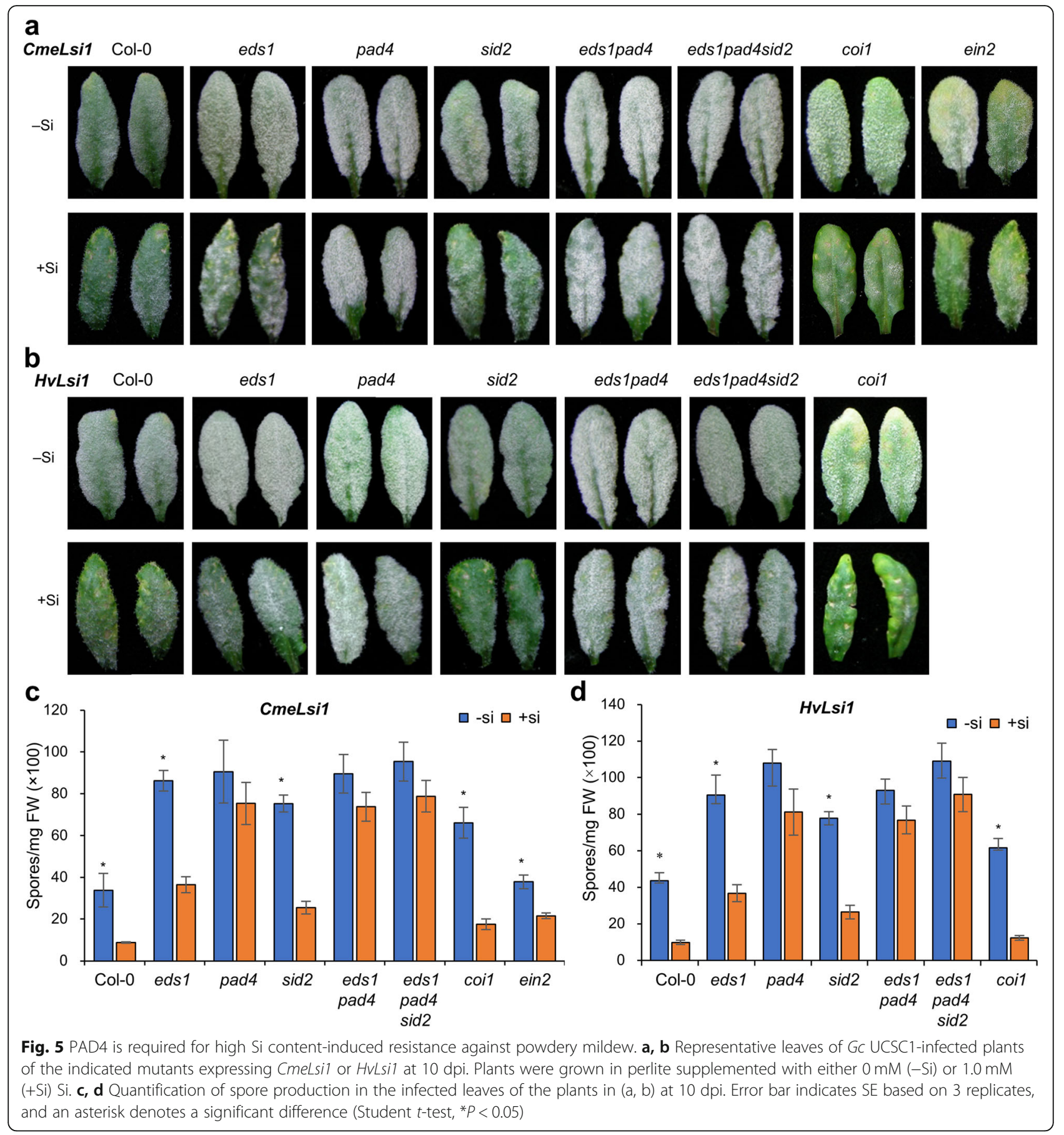

found that although PAD4 was induced to higher levels by powdery mildew infection at 3 and $5 \mathrm{dpi}$, no significant difference was detected between $-\mathrm{Si}$ and $+\mathrm{Si}$ plants (Additional file 1: Figure S4). This result suggests that highlevel Si may not impact transcription of PAD4 but rather augment certain functionality of $P A D 4$ via an unknown post-transcriptional mechanism, thereby activating this defense pathway. Not surprisingly, we detected no significant difference in PDF1.2 expression between $-\mathrm{Si}$ and $+\mathrm{Si}$ plants before and after powdery mildew infection (Additional file 1: Figure S4), which was consistent with the observation that no significant phenotypic difference was found between transgenic lines of Col-0 and those of coil (Fig. 5). We also measured PMR4 expression under different $\mathrm{Si}$ conditions given that the callose formation and deposition may coordinate with biological silicification in Arabidopsis (Brugiére and Exley 2017). The result showed that $\mathrm{Si}$ content had little impact on PMR4 expression 
(Additional file 1: Figure S4). To further test if the PAD4dependent, high Si-conditioned resistance is influenced by SA or JA biosynthesis, we also measured the total SA, free $\mathrm{SA}$ and JA levels in the transgenic $-\mathrm{Si}$ and $+\mathrm{Si}$ plants and found that levels of total SA were significantly higher in HvLsi1-Col-0/+Si plants compared to the plants of the same line with $-\mathrm{Si}$ treatment before and after powdery mildew infection (Additional file 1: Figure S5). As expected, the levels of total SA and free SA were significantly lower in transgenic eds1, pad4, and particularly sid2 lines in comparison with those of transgenic Col-0 under either $-\mathrm{Si}$ or $+\mathrm{Si}$ conditions (Additional file 1: Figure S5). Interestingly, compared with the respective -Si plants, JA levels

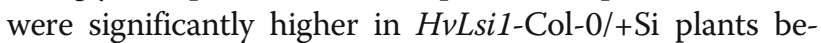
fore and after powdery mildew infection, so were the total SA and JA levels in HvLsi1-eds1/+Si, HvLsi1-pad4/+Si, and HvLsi1-sid2/+Si plants in general (except in the case of total SA in the sid2 background) (Additional file 1: Figure S5). However, the lack of correlation between either total SA or JA levels and high Si-mediates resistance suggests that increased SA or JA levels cannot explain PAD4-dependent, high Si-mediated resistance in Arabidopsis.

\section{Elevated Si can largely restore resistance to a non-} adapted powdery mildew in an immunocompromised triple mutant

G. cichoracearum (Gc) UMSG1 infects sow thistle (Sonchus oleraceus) but fails to reproduce on 25 tested Arabidopsis accessions including Col-0, even though it has largely overcome penetration resistance of Arabidopsis (Wen et al. 2010). Thus, by definition, Gc UMSG1 is still a non-adapted powdery mildew pathogen of Arabidopsis. However, the triple mutant eds1pad4sid2 (in the background of Col-0) is nearly fully susceptible to Gc UMSG1, indicating breakdown of non-host resistance of Col-0 (Zhang et al. 2018). To test if increased Si content can compensate the loss of the non-host resistance, we inoculated plants of HvLsi1-eds1pad4sid2 and CmeLsi1eds1pad4sid2 with or without Si supplement with Gc UMSG1. Visual examination of the infection phenotypes at $10 \mathrm{dpi}$ showed that while there was no obvious difference between $-\mathrm{Si}$ and $+\mathrm{Si}$ plants of eds1pad4sid2, there was remarkably increased resistance in $+\mathrm{Si}$ plants but not seen in -Si plants of the same HvLsi1- or CmeLsi1-transgenic lines (Fig. 6a). Spore counting showed that there was a $\sim 17$-fold reduction in sporulation in infected plants of

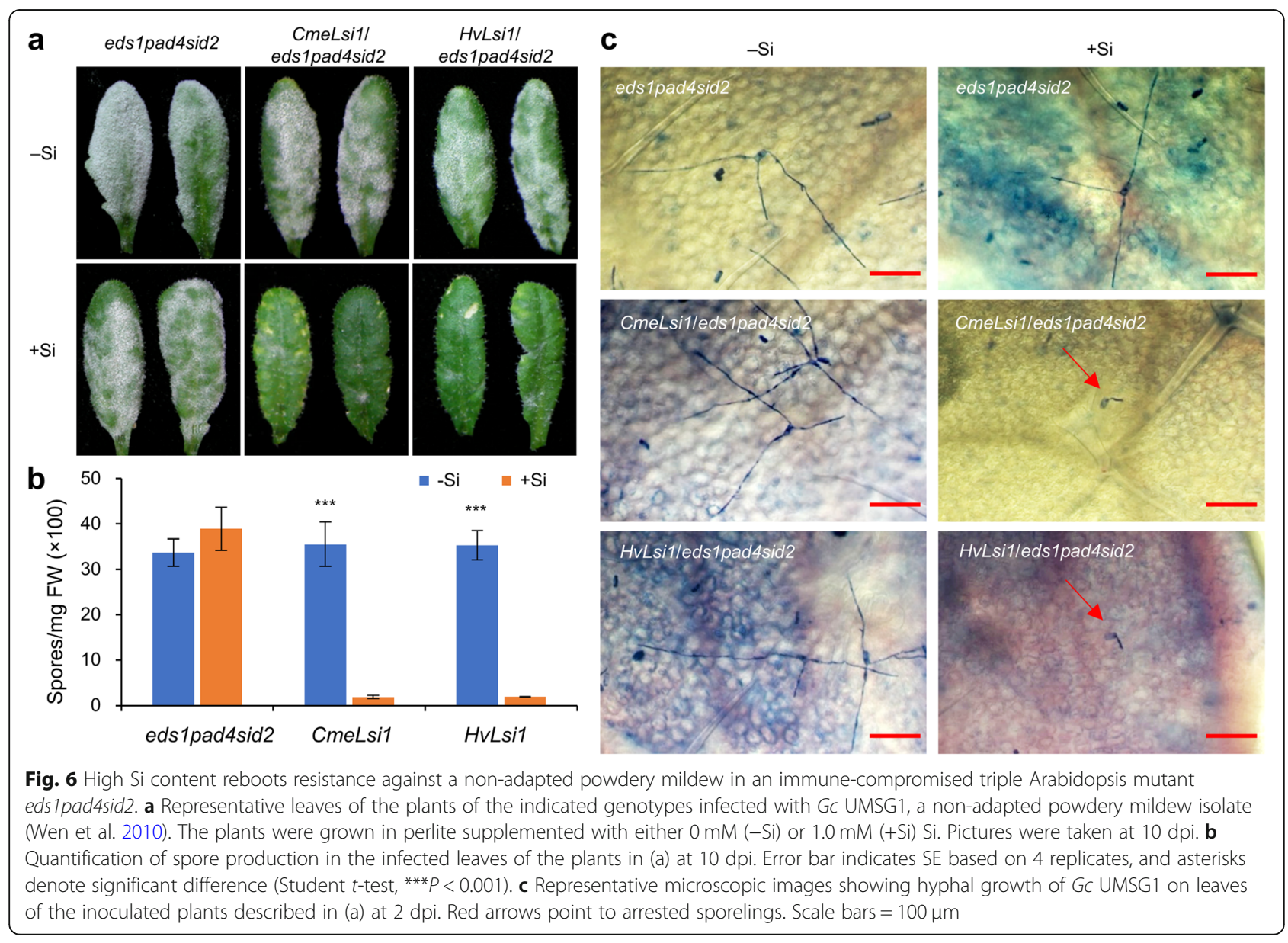


the same transgenic lines treated with $\mathrm{Si}$ versus those without $\mathrm{Si} \mathrm{(Fig.} \mathrm{6b).} \mathrm{These} \mathrm{results} \mathrm{indicate} \mathrm{that} \mathrm{high} \mathrm{leaf} \mathrm{Si}$ content can largely compensate the loss of EDS1, PAD4 and SID2 and reboot resistance to a non-adapted powdery mildew pathogen via an EDS1-, PAD4- and SID2independent mechanism.

Gc UMSG1 is arrested after its penetration of the cell wall in leaves of Col-0 (Wen et al. 2010). To find out at what stage Gc UMSG1 was arrested in plants of HvLsi1- or CmeLsi1- eds1pad4sid2/+Si lines, we examined fungal growth in the leaves of the same transgenic lines under $\mathrm{Si}$ or $+\mathrm{Si}$ conditions at $2 \mathrm{dpi}$ and $5 \mathrm{dpi}$ using Trypan Blue staining. We found that appressorial penetration of sporelings was almost completely restricted in $+\mathrm{Si}$ transgenic plants at $2 \mathrm{dpi}$ (Fig. $6 \mathrm{c}$ ), with only rare exceptions $(\sim 1 / 20$ sporelings) where the sporelings further differentiated limited hyphae at 5 dpi (Additional file 1: Figure S6), some of which eventually continued to grow into sporadic colonies with sporulation at $10 \mathrm{dpi}$ (Fig. 6a). These observations suggest that high Si content can largely restore the penetration resistance lost in the immunocompromised Arabidopsis mutant plants against the non-adapted Gc UMSG1 isolate. This resistance mechanism is obviously different from that of the PAD4-dependent resistance mediated by high $\mathrm{Si}$ against the well-adapted Gc UCSC1 isolate where no gross difference in hyphal growth of sporelings at 2 dpi was observed between $-\mathrm{Si}$ and $+\mathrm{Si}$ plants (Additional file 1: Figure S7).

\section{Discussion}

$\mathrm{Si}$ has long been known to increase disease resistance in plants. The suppressive effect of Si on powdery mildew was first reported in 1983 (Miyake and Takahashi 1983). However, the molecular mechanisms underlying Si-mediated resistance remain largely elusive and even controversial till today. In this study, by using the Arabidopsis-powdery mildew pathosystem, we collected genetic evidence to demonstrate that $\mathrm{Si}$ affects different layers of plant defense in a dosage-dependent manner, providing novel mechanistic insights into Si's prophylactic role in plants against fungal pathogens.

A few previous studies on how Si might affect basal resistance to adapted powdery mildew using Arabidopsis Col-0 wild-types did not generate consistent results (Ghanmi et al. 2004; Fauteux et al. 2006; Vivancos et al. 2015). One contributing factor might be that different types or even batches of commercial soil for growing Arabidopsis may vary in Si content. This prompted us to use perlite as soil medium (Xiao et al. 2003) in this study to enable tighter control of $\mathrm{Si}$ supplement, which led to our observation that Col-0 plants with a very low leaf $\mathrm{Si}$ content $(<2.0 \mathrm{mg} / \mathrm{g})$ displayed slightly but visually discernable and statistically significant enhanced resistance against the adapted powdery mildew Gc UCSC1 (Fig. 1).
The resistance was found to be associated with $\mathrm{H}_{2} \mathrm{O}_{2}$ accumulation in the invaded cells and require intact SAsignaling (Fig. 3). Interestingly, a previous study also showed that oat plants deprived for Si exhibited higher phenylalanine ammonia lyase activity compared to those with normal Si supply, which led to a speculation that lack of Si may activate a compensatory mechanism resulting in better resistance to powdery mildew penetration resistance (Carver et al. 1998). Hence, we speculate that $\mathrm{Si}$ content below a certain threshold level $(<2.0$ $\mathrm{mg} / \mathrm{g}$ for Arabidopsis leaves) may produce a warning signal in plant cells to activate and/or potentiate SA signaling. Considering the positive role of high $\mathrm{Si}$ in plant resistance against powdery mildew pathogens based on data from this and other studies (Bélanger et al. 2003; Vivancos et al. 2015), the Si dosage-impact characteristics we observed is reminiscent of the case concerning PMR4-dependent callose: Whereas deposition of callose can strengthen the papilla as a physical barrier and more extensive and faster deposition of callose by overexpression of the responsible callose synthase PMR4 confers complete resistance to powdery mildew (Ellinger et al. 2013), loss of PMR4 also results in enhanced resistance to powdery mildew (Nishimura et al. 2003). Such functional similarity between $\mathrm{Si}$ and callose may imply mechanistic connection between them. We thus checked if callose deposition is affected in powdery mildew-infected Col-0/-Si plants. Interestingly, we found that very low Si appeared to increase callose deposition to the papilla (Additional file 1: Figure S8), possibly as an indirect consequence of enhanced SA-dependent defenses in Col-0/-Si plants.

Vivancos and colleagues used Arabidopsis Col-0 transgenic for wheat Si influx transporter (TaLsi1) to demonstrate that high $\mathrm{Si}$ absorbed by Arabidopsis can increase resistance to an adapted powdery mildew isolate (Vivancos et al. 2015). However, they showed that the high $\mathrm{Si}$-enhanced resistance was not affected by the loss of PAD4 or SID2, which differs from our result that high Si-mediated resistance is PAD4-dependent (Fig. 3). Our conclusion was inferred from the infection phenotypes of wild-type, single, double and triple pad4containing transgenic lines expressing one of the two selected heterologous Si transporters using very even conidia inoculation (see Methods for details). It is possible that the discrepancy concerning PAD4 might have been caused by the differences in powdery mildew inoculation and/or growth conditions. Nevertheless, our results corroborated with their conclusion that high Si enhances SA-independent resistance to powdery mildew. The PAD4-dependence of high Si-mediated resistance is particularly interesting, because it suggests that high Si may activate or potentiate an intracellular defense mechanism beyond apoplastic obstruction (Coskun et al. 2019). Moreover, it also suggests that 
this PAD4-dependent mechanism is distinct from that activated by PAD4 and its partner EDS1 in SAdependent resistance against biotrophic and hemibiotrophic pathogens (Falk et al. 1999; Jirage et al. 1999; Feys et al. 2001). Thus, our results resemble the earlier finding that PAD4, but not EDS1, contributes to resistance of Arabidopsis to green peach aphids (GPA) (Pegadaraju et al. 2007). PAD4 has also been shown to be required for the enhanced resistance to GPA in two Arabidopsis mutants exhibiting heightened resistance against biotrophic pathogens (Louis et al. 2010; Louis et al. 2012; Lei et al. 2014). Given that Si has also been shown to increase resistance to piercing and sucking (phloem-feeding) insects including aphids (Reynolds et al. 2009), one may speculate that PAD4 also plays a similar role in Si-heightened resistance against insects. How PAD4 contributes to resistance (exerted by high $\mathrm{Si}$ ) against pathogens and GPA (and potentially other insects when plants are supplemented with $\mathrm{Si}$ ) via a largely SA-independent pathway is currently unknown. There are reports that implicate JA-dependent defense in Si-mediated resistance to pathogens (Ghareeb et al. 2011) and insects (Ye et al. 2013). In this study, we did find higher JA levels in + Si plants; however, we cannot establish a role of JA-signaling in high Si-mediated resistance because JA-signaling deficient coil mutant plants transgenic for either of the two heterologous $\mathrm{Si}$ transporter genes under $+\mathrm{Si}$ conditions also showed resistance (Fig. 5). Similar results were reported for Si-induced brown spot resistance (Van Bockhaven et al. 2015). The increased JA levels in all HvLsi1-transgenic $\mathrm{Col}-\mathrm{O} /+\mathrm{Si}$ plants may be associated with high Si-caused toxicity manifested as whitish spots in Arabidopsis leaves (Additional file 1: Figure S9), which apparently did not affect powdery mildew infection as pad4-containing transgenic plants supplemented with high $\mathrm{Si}$ were very susceptible despite having similar whitish spots (Fig. 5). Such toxicity was also observed when TaLsi1 and OsLsi1 were expressed in Arabidopsis using the $35 S$ promoter but was largely absent when a root specific promoter was used (Montpetit et al. 2012).

Apart for the unexpected finding with regard to PAD4-dependent Si-mediated resistance, another surprising observation from this study is the high $\mathrm{Si}$ mediated restoration of penetration resistance in the eds1pad4sid2 triple mutant background to Gc UMSG1 (Fig. 6). This finding has several implications: First, Si may play an important role in blocking the entry of numerous non-adapted and probably poorly-adapted cellwall penetrating fungal pathogens and perhaps insects. Such a role cannot be easily revealed unless an artificial pathosystem such as eds1pad4sid2-Gc UMSG1 is used, thus demonstrating the power of such a system.
Second, that $\mathrm{Si}$-mediated penetration resistance against non-adapted powdery mildew pathogens can occur in the absence of EDS1, PAD4 and SID2 implies that Si deposition to the cell wall and papillae is probably a mechanical process independent of the immunity status of the plant. Third, adapted powdery mildew, by definition, can largely overcome this physical barrier.

In summary, results from this study implicated $\mathrm{Si}$ in three unexpected and distinct defense mechanisms that lead to enhanced resistance to powdery mildew: (1) very low Si-triggered SA-dependent defense; (2) high Si-mediated PAD4-dependent defense; and (3) high Si-boosted penetration resistance. How to make sense of these seemingly distinct mechanisms? Information from previous reports (see below) and this study as a whole appears to support the "Si-callose synergy theory" (Brugiére and Exley 2017) which may offer a plausible explanation for our observations. First, $\mathrm{Si}$ is deposited to callose-rich papillae thereby playing a positive role in restricting cell-wall penetrating fungal pathogens such as powdery mildew (Carver et al. 1998; Bélanger et al. 2003; Shetty et al. 2012). Second, cell wall silicification appears to require callose and may be initiated by callose (Brugiére and Exley 2017; Kulich et al. 2018). Third, either very low Si (Fig. 1) or lack of callose (due to loss of PMR4/ GSL5) (Nishimura et al. 2003) triggers SA-dependent defense. Fourth, either high Si (Fig. 3) or overexpression of PMR4/GSL5 (Ellinger et al. 2013) confers resistance to powdery mildew. Lastly, PAD4-dependent resistance to aphids is also associated with increased callose deposition (Rashid et al. 2017), similar to Simediated resistance to insects (Yang et al. 2018) or even nematodes (Zhan et al. 2018), despite that in the latter cases whether resistance is PAD4-dependent remains to be tested. Therefore, it is possible that PAD4 (but not EDS1) may play a critical role in the deposition of a basal level of PMR4-dependent callose to papillae, thus explaining the PAD4-dependence of high Si-mediated resistance against powdery mildew pathogens. Combining all the above information, we developed a schematic diagram to summarize our genetic data on $\mathrm{Si}$ and hypothesize that deposition of $\mathrm{Si}$, along with callose, to the papilla in plant cells enhances defense against powdery mildew infection in three different scenarios (Fig. 7). Future research is needed to investigate whether and how $\mathrm{Si}$ and callose may synergize with each other to fortify cell wallbased defense against fungal invasion, how exactly PAD4 regulates this defense mechanism, whether $\mathrm{Si}$-mediated resistance to insects also requires a PAD4-regulatory node, and whether this mechanistic model is also applicable to medium- and high-Siaccumulating plants. 

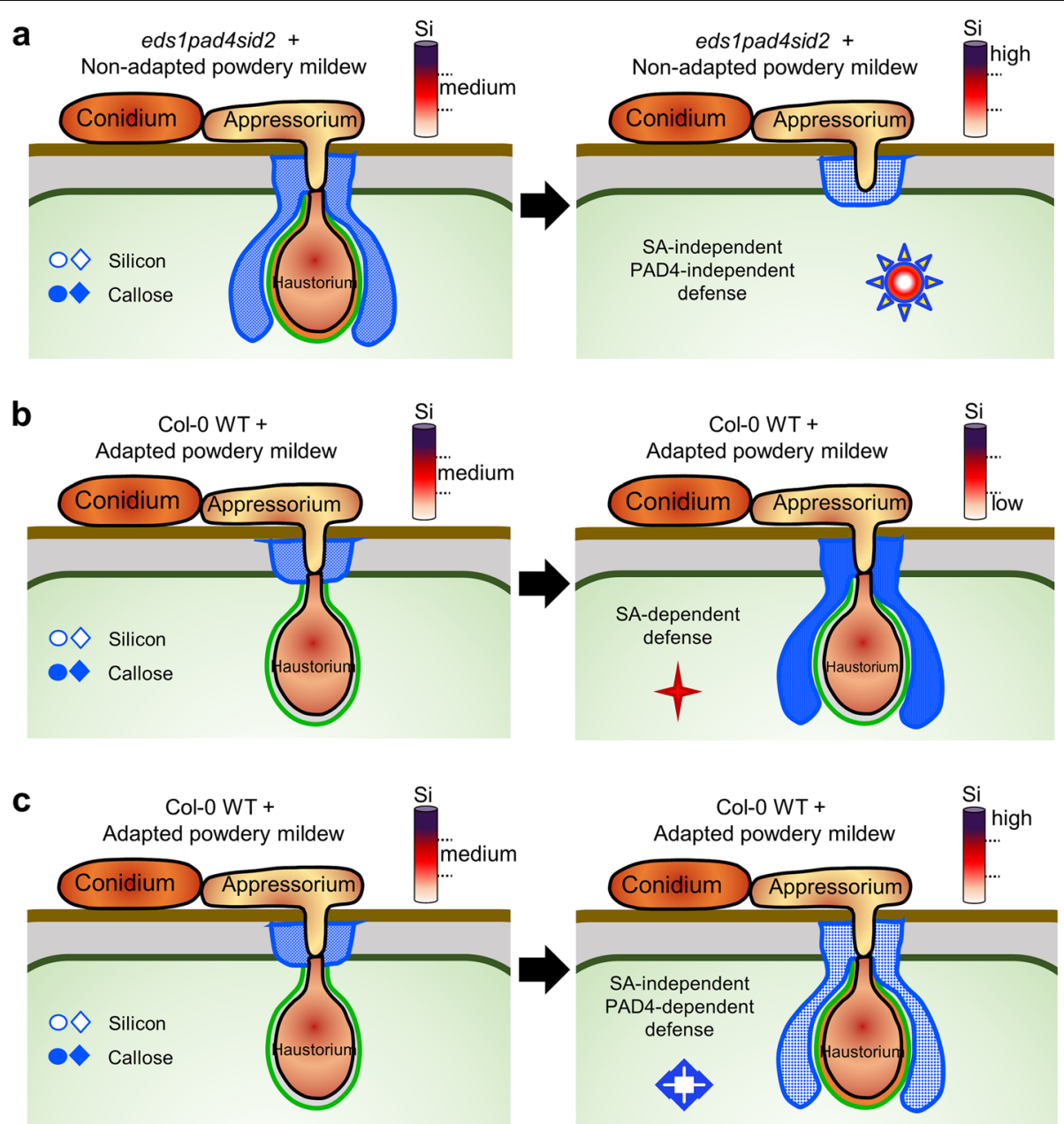

Fig. 7 Schematic diagram describing the three scenarios where very low Si or high Si confers enhanced resistance to powdery mildew, and the potential synergistic action between Si and callose. Based on publish results and our observations from this study, we speculate that Si may polymerize with cell wall components especially callose to fortify the cell wall as a major preformed physical barrier to defend plant cells against cell wall-penetrating non- and poorly-adapted pests such as powdery mildew. Compromised resistance against such pathogens due to loss of EDS1, PAD4 and SID2 can be compensated by more Si deposition (a). Adapted powdery mildew has largely overcome this physical barrier; however, depriving Si or callose from such structures may generate a warning signal to activate SA-dependent defense that can promote the callose-rich papilla to further "grow" to (half) encase the haustorium (Meyer et al. 2009), limiting the growth of the adapted powdery mildew (b). High Si can strengthen the papilla and the callosic encasement, which requires a PAD4-dependent (but SA-independent) mechanism, resulting in enhanced basal resistance (c)

\section{Conclusions}

Through the use of Arabidopsis genetic mutants, transgenic expression of heterologous Si transporters and a more stringent control of Si supply, we found that Arabidopsis plants containing either very low or very high $\mathrm{Si}$ content displayed enhanced resistance to powdery mildew. Interestingly, we found that whereas very low Si-induced resistance is SA-dependent, high Si-mediated resistance is indeed largely independent of SA signaling but surprisingly requires PAD4. Moreover, we also found that high Si can effectively reboot penetration resistance in a SA signaling-defective and PAD4-ablated Arabidopsis mutant that is otherwise fully susceptible to a non-adapted powdery mildew isolate. Thus, our results present genetic evidence for the role of $\mathrm{Si}$ in multi-layered plant defense mechanisms, which should help clarify the current confusion and controversy over the molecular mechanisms underlying Si's positive role in plant disease resistance against fungal pathogens.

\section{Methods}

\section{Plant lines and growth conditions}

All mutants used in this study were in the Arabidopsis thaliana accession Col-0 background. Mutants eds1 (eds1-2), pad4 (pad4-1), sid2 (sid2-2), eds1pad4 (eds12pad4-1), eds1pad4sid2 (eds1-2pad4-1sid2-2), coi1 (coi1-1) have been described previously by Zhang et al. (2018). Mutant ein2 (ein2-1) has been described by Guzman and Ecker (1990). Seeds were sown in Propagation Mix (Sun Gro Horticulture, Massachusetts) and 
cold treated $\left(4{ }^{\circ} \mathrm{C}\right.$ for 2 days), and seedlings were grown under $22{ }^{\circ} \mathrm{C}, 65 \%$ relative humidity, short day $(10 \mathrm{~h}$ light at $125 \mu \mathrm{mol} / \mathrm{m}^{2} / \mathrm{s}, 14 \mathrm{~h}$ dark). For Si experiments, 12-day-old seedlings grown in regular soil (Propagation Mix) were transplanted into pots containing horticultural perlite (Whittemore). Plants were irrigated with nutrient solution prepared with deionized pure water. The nutrient solution was prepared based on Boursiac et al. (2010) with some modifications $\left(\mathrm{pH} 5.8 ; 1.5 \mathrm{mM} \quad \mathrm{Ca}\left(\mathrm{NO}_{3}\right)_{2} \cdot 4 \mathrm{H}_{2} \mathrm{O}, 1.25 \mathrm{mM} \mathrm{KNO}_{3}\right.$, $0.5 \mathrm{mM} \quad \mathrm{KH}_{2} \mathrm{PO}_{4}, 0.75 \mathrm{mM} \quad \mathrm{MgSO}_{4} \cdot 7 \mathrm{H}_{2} \mathrm{O}, 0.046 \mathrm{mM}$ $\mathrm{H}_{3} \mathrm{BO}_{3}, 9.55 \mu \mathrm{M} \mathrm{MnSO}_{4} \cdot 4 \mathrm{H}_{2} \mathrm{O}, 0.77 \mu \mathrm{M} \mathrm{ZnSO}_{4} \cdot 7 \mathrm{H}_{2} \mathrm{O}$, $0.32 \mu \mathrm{M} \mathrm{CuSO}_{4} \cdot 5 \mathrm{H}_{2} \mathrm{O}, 0.016 \mu \mathrm{M}\left(\mathrm{NH}_{4}\right)_{6} \mathrm{Mo}_{7} \mathrm{O}_{24} \cdot 4 \mathrm{H}_{2} \mathrm{O}$, $0.054 \mathrm{mM}$ EDTA-bisodium salt). When plants were 6 weeks old, half of them were irrigated with nutrient solution containing $1.0 \mathrm{mM} \mathrm{Na}_{2} \mathrm{SiO}_{3} \cdot 9 \mathrm{H}_{2} \mathrm{O}(+\mathrm{Si})$, the other half were irrigated with nutrient solution containing $1.0 \mathrm{mM} \mathrm{Na}_{2} \mathrm{SO}_{4}(-\mathrm{Si})$.

\section{DNA constructs and generation of transgenic lines}

To make Arabidopsis absorb more $\mathrm{Si}$ from soil medium, we generated stable transgenic lines of Col-0 wild-type and various mutants that express $H v L s i 1$ (a barley $\mathrm{Si}$ transporter gene; GenBank accession LOC100301576) or CmeLsi1(a muskmelon Si transporter gene; GenBank accession LOC103487002) from the $35 \mathrm{~S}$ promoter. Briefly, total RNA was extracted from roots of barley (Hordeum vulgare L.) or muskmelon (Cucumis melo L.) using the TRIZOL reagent (Invitrogen) according to the manufacturer's recommendations and stored at $-80^{\circ} \mathrm{C}$ until use. First strand cDNAs were prepared from $1 \mu \mathrm{g}$ of total RNA using a reverse transcriptase (superscript III, Invitrogen) and Oligo (dT)18 primers. The coding sequences of HvLsi1 and CmeLsi1 were amplified with the Q5 DNA polymerase (New England Biolabs, M0491L) with appropriate primer pairs (Additional file 2: Table S1). The DNA fragments were cloned into pENTR/DTOPO (Thermo Fisher Scientific Inc.) and shuttled to the Gateway Compatible binary vector pEarleyGate100. After DNA sequence confirmation, the constructs were introduced into Arabidopsis plants via Agrobacterium-mediated transformation using the $A$. tumefaciens strain GV3101. At least 20 independent T1 transgenics were obtained for each DNA construct/genotype combination. T2 progenies (24 plants) of at least ten $\mathrm{T} 1$ lines were grown under $-\mathrm{Si}$ and + $\mathrm{Si}$ conditions and inoculated with powdery mildew to visually assess the infection phenotypes. T3 generations derived from three $\mathrm{T} 1$ independent lines were used to confirm the infection phenotypes, and one representative homozygous T3 line for each genotype was used for comparative and quantitative analysis with other relevant genotypes.

\section{Pathogen infection and quantification of disease phenotypes}

Adapted powdery mildew isolate G. cichoracearum (Gc) UCSC1 was maintained on pad4 plants and the nonadapted isolate Gc UMSG1 was maintained on sow thistle plants (Wen et al. 2010). Inoculation and visual scoring of disease reaction phenotypes and spore quantification were done as previously described (Zhang et al. 2018). Briefly, for quantification of disease susceptibility, five or six duplicate leaf samples (each consisting of $\sim 120 \mathrm{mg}$ leaves) collected from 12 plants of each representative T3 line at 10 dpi were used to quantify the level of sporulation. A spore suspension (or 10x dilution if the genotype was very susceptible) of each sample, which was made by vortexing the leaves in a $50 \mathrm{~mL}$ falcon tube containing $10 \mathrm{~mL}$ of $\mathrm{H}_{2} \mathrm{O}+$ 0.02\% Silwet L-77 (Lehle seeds, USA) for $1 \mathrm{~min}$, was used for spore counting using Luna ${ }^{\mathrm{T}}$ Automated Cell Counter (Logos biosysems). Spore counts were normalized to the fresh weight of the corresponding leaf samples. All infection trials with T3 generations were repeated three times with similar results, and data from one experiment were presented.

\section{Detection of $\mathrm{H}_{2} \mathrm{O}_{2}$, callose deposition and fungal structures}

The detection of $\mathrm{H}_{2} \mathrm{O}_{2}$ accumulation in leaf tissues by 3, 3-diaminobenzidine (DAB) staining was modified from Thordal-Christensen et al. (1997). Inoculated leaves were excised at the base of the petiole, placed in $1 \mathrm{mg} / \mathrm{mL}$ DAB (Sigma), and incubated for $6 \mathrm{~h}$ at $25^{\circ} \mathrm{C}$ with illumination. Fungal structures in inoculated leaves were visualized with $0.25 \%$ Trypan blue staining solution (Xiao et al. 2003). Callose deposition at the fungal penetration sites (i.e. papillae) and around the haustorium was detected by aniline blue staining. Leaves were cleared in a solution containing ethanol, water, acetic acid, and glycerol $(8: 1: 1: 1)$ for $48 \mathrm{~h}$ at $37^{\circ} \mathrm{C}$ with one change of the solution. The cleared leaves are then stained with $0.01 \%$ aniline blue in an aqueous solution containing $150 \mathrm{mM}$ $\mathrm{KH}_{2} \mathrm{PO}_{4}$ (PH 9.5) for $4 \mathrm{~h}$. Callose deposition was visualized by fluorescence microscopy.

\section{Measurement of Si content in Arabidopsis leaves}

Leaf $\mathrm{Si}$ content was determined 10 days after treatment with $+\mathrm{Si}$ or $-\mathrm{Si}$ nutrient solution using 7 or 8 -week-old plants. All rosette leaves from five $+\mathrm{Si}$ or $-\mathrm{Si}$ plants per sample were oven dried at $65^{\circ} \mathrm{C}$ for $72 \mathrm{~h}$, and ground into a fine powder using a mortar and pestle before measurement of $\mathrm{Si}$ concentration by colorimetric analysis using $0.1 \mathrm{~g}$ alkali-digested leaf tissue powder (Frantz et al. 2008). Si content was calculated, adjusted for dry weight of leaf tissues used, and presented as mg Si dioxide per gram dry matter. 


\section{qRT-PCR analysis}

Gene expression was measured by qRT-PCR according to Zhang et al. (2018) with minor modification. Five duplicate leaf samples ( $100 \mathrm{mg}$ each) per genotypetreatment were collected at 0,3 and 5 dpi with Gc UCSC1. The transcript levels of the target genes were normalized to that of UBC9 (Ubiquitin conjugating enzyme 9, AT4G27960). Data were analyzed by using the comparative $\Delta \Delta \mathrm{Ct}$ method (Livak and Schmittgen 2001). Primers are listed in Additional file 2: Table S1.

\section{Measurement of levels of SA and JA}

Five leaf samples $(\sim 150 \mathrm{mg}$ each $)$ per genotypetreatment were harvested at 0,3 and 5 dpi with $G c$ UCSC1 for determining levels of both SA and JA as previously described (Floková et al. 2014), with some modifications. For each experiment, detection was performed with three biological replicates per treatment. The leaf tissues in a $1.5 \mathrm{~mL}$ tube were added with $1 \mathrm{~mL}$ of $50 \%$ ethanol containing the internal standards (vanillic acid and dihydro jasmonic acid), four steel balls (diameter 5 $\mathrm{mm}$ ), and then shaken for $5 \times 1 \mathrm{~min}$ in a TissueLyser II (QIAGEN) at $25 \mathrm{~Hz}$ with $1 \mathrm{~min}$ pause between every minute before centrifugation at $20,000 \times \mathrm{g}$ for $10 \mathrm{~min}$. The supernatant was analyzed with a Waters Acquity UPLC system equipped with a Waters LCT Premiere XE ESITOF mass spectrometer.

SA and JA levels were detected with the above system. Four microliter injections of leaf tissue supernatant were made and phytohormones were separated using a Waters HSS C18 column $(2.1 \mathrm{~mm} \times 100 \mathrm{~mm} ; 1.7 \mu \mathrm{m}$ particle size). A binary solvent system consisting of $0.1 \%$ formic acid (solvent $\mathrm{A}$ ) and $0.1 \%$ formic acid in acetonitrile (solvent B) was used. Gradient conditions were: $0-1$ min, $20 \%$ solvent $\mathrm{B} ; 1-3.5 \mathrm{~min}$, a linear gradient to $90 \%$ solvent B; $3.5-4 \mathrm{~min}, 90 \%$ solvent $\mathrm{B}$. The flow rate was $0.35 \mathrm{~mL} / \mathrm{min}$. Phytohormones were quantified via mass spectrometry by integrating extracted ion chromatogram peak areas for compounds of interest. Compounds were detected in negative ion mode using the following parameters: Capilliary voltage $2150 \mathrm{~V}$, cone voltage $20 \mathrm{~V}$, desolvation temperature $275^{\circ} \mathrm{C}$, desolvation gas flow $250 \mathrm{~L} / \mathrm{h}$, cone gas flow $15 \mathrm{~L} / \mathrm{h}$, source temperature $115^{\circ} \mathrm{C}$. Standard curves were constructed using authentic phytohormone standards.

\section{Supplementary information}

Supplementary information accompanies this paper at https://doi.org/10. 1186/s42483-020-00048-9.

Additional file 1: Figure S1. GC UCSC1 infection phenotypes of Col-0 plants grown in soil matrix treated with $0 \mathrm{mM} \mathrm{Si}, 1.7 \mathrm{mM}$ Si or tap water. Figure S2. Silicon content in deionized water and tap water, different soil media, and in leaves of Col-0 plants grown in regular soil matrix or perlite. Figure S3. Silicon content in leaves of different Arabidopsis lines and their respective transgenic lines expressing a heterologous Si transporter. Figure S4. Expression levels of defense-related genes in transgenic Col-0 overexpressing HvLsi1. Figure S5. Levels of total SA, free SA and JA in Arabidopsis plants overexpressing HVLsi1. Figure S6. Microscopic images showing fungal microcolonies grown on leaves at $5 \mathrm{dpi}$. Figure S7. Microscopic images showing fungal microcolonies grown on leaves at 2 dpi. Figure S8. Callose deposition in Arabidopsis Col-0 leaves inoculated with $G$. cichoracearum UCSC1. Figure S9. Leaf phenotypes of Col-0 and pad4-1 and their transgenic plants overexpressing the indicated Si transporter grown in perlite without Si or with $1.0 \mathrm{mM}$ Si.

Additional file $\mathbf{2}$ : Table S1. Primers used in this work.

\section{Abbreviations}

ET: Ethylene; Gc: Golovinomyces cichoracearum; Gc UCSC1: The adapted powdery mildew isolate Golovinomyces cichoracearum UCSC1; GC

UMSG1: The non-adapted powdery mildew isolate Golovinomyces cichoracearum UMSG1; JA: Jasmonic acid; SA: Salicylic acid; Si: Silicon

\section{Acknowledgments}

We thank Franker Coker for maintaining the plant growth facilities.

\section{Authors' contributions}

$X D, L W$ and SX conceived and designed the experiments. LW, MD, YW, QZ, LH, EE and JFP performed experiments and analyzed data. LW and SX wrote the manuscript. All authors read and approved the final manuscript.

\section{Funding}

This work was supported by a National Science Foundation grant (IOS1457033) and a Maryland Horticultural Society grant (2017) to SX, and a scholarship from the China Scholarship Council to LW.

\section{Availability of data and materials}

The datasets used and/or analysed during the current study are available from the corresponding author on reasonable request.

Ethics approval and consent to participate

Not applicable.

\section{Consent for publication}

Not applicable.

\section{Competing interests}

The authors declare that they have no competing interests.

\section{Author details}

${ }^{1}$ College of Plant Protection, China Agricultural University, Beijing 100193, China. ${ }^{2}$ Institute for Bioscience and Biotechnology Research, University of Maryland, Rockville, MD 20850, USA. ${ }^{3}$ Fischell Department of Bioengineering, University of Maryland, College Park, MD 20742, USA. ${ }^{4}$ Department of Plant Science and Landscape Architecture, University of Maryland, College Park, MD 20742, USA.

Received: 6 February 2020 Accepted: 16 March 2020

Published online: 27 March 2020

References

Bélanger RR, Benhamou N, Menzies JG. Cytological evidence of an active role of silicon in wheat resistance to powdery mildew (Blumeria graminis f. sp. tritici). Phytopathology. 2003;93:402-12.

Boursiac Y, Lee SM, Romanowsky S, Blank R, Sladek C, Chung WS, et al. Disruption of the vacuolar calcium-ATPases in Arabidopsis results in the activation of a salicylic acid-dependent programmed cell death pathway. Plant Physiol. 2010;154:1158-71.

Brugiére T, Exley C. Callose-associated silica deposition in Arabidopsis. J Trace Elem Med Biol. 2017:39:86-90.

Brunings AM, Datnoff LE, Ma JF, Mitani N, Nagamura Y, Rathinasabapathi B, et al. Differential gene expression of rice in response to silicon and rice blast fungus Magnaporthe oryzae. Ann Appl Biol. 2009;155:161-70.

Carver TLW, Robbins MP, Thomas BJ, Troth K, Raistrick N, Zeyen RJ. Silicon deprivation enhances localized autofluorescent responses and phenylalanine 
ammonia-lyase activity in oat attacked by Blumeria graminis. Physiol Mol Plant Pathol. 1998:52:245-57.

Chain F, Côté-Beaulieu C, Belzile F, Menzies JG, Bélanger RR. A comprehensive transcriptomic analysis of the effect of silicon on wheat plants under control and pathogen stress conditions. Mol Plant-Microbe Interact. 2009;22:1323-30.

Chiba Y, Mitani N, Yamaji N, Ma JF. HvLsi1 is a silicon influx transporter in barley. Plant J. 2009;57:810-8.

Coskun D, Deshmukh R, Sonah H, Menzies JG, Reynolds O, Ma JF, et al. The controversies of silicon's role in plant biology. New Phytol. 2019;221:67-85.

Ellinger D, Naumann M, Falter C, Zwikowics C, Jamrow T, Manisseri C, et al. Elevated early callose deposition results in complete penetration resistance to powdery mildew in Arabidopsis. Plant Physiol. 2013;161:1433-44.

Epstein E. The anomaly of silicon in plant biology. Proc Natl Acad Sci U S A. 1994; 91:11-7.

Falk A, Feys BJ, Frost LN, Jones JDG, Daniels MJ, Parker JE. EDS1, an essential component of $R$ gene-mediated disease resistance in Arabidopsis has homology to eukaryotic lipases. Proc Natl Acad Sci U S A. 1999;96:3292-7.

Fauteux F, Chain F, Belzile F, Menzies JG, Bélanger RR. The protective role of silicon in the Arabidopsis-powdery mildew pathosystem. Proc Natl Acad Sci U S A. 2006;103:17554-9.

Feys BJ, Moisan LJ, Newman MA, Parker JE. Direct interaction between the Arabidopsis disease resistance signaling proteins, EDS1 and PAD4. EMBO J. 2001;20:5400-11.

Floková K, Tarkowská D, Miersch O, Strnad M, Wasternack C, Novák O. UHPLCMS/MS based target profiling of stress-induced phytohormones. Phytochemistry. 2014;105:147-57.

Frantz JM, Locke JC, Datnoff L, Omer M, Widrig A, Sturtz D, et al. Detection, distribution, and quantification of silicon in floricultural crops utilizing three distinct analytical methods. Commun Soil Sci Plant Anal. 2008;39:2734-51.

Ghanmi D, McNally DJ, Benhamou N, Menzies JG, Bélanger RR. Powdery mildew of Arabidopsis thaliana: a pathosystem for exploring the role of silicon in plant-microbe interactions. Physiol Mol Plant Pathol. 2004;64:189-99.

Ghareeb H, Bozsó Z, Ott PG, Repenning C, Stahl F, Wydra K. Transcriptome of silicon-induced resistance against Ralstonia solanacearum in the silicon nonaccumulator tomato implicates priming effect. Physiol Mol Plant Pathol. 2011;75:83-9.

Guzman P, Ecker JR. Exploiting the triple response of Arabidopsis to identify ethylene-related mutants. Plant Cell. 1990;2:513-23.

Jirage D, Tootle TL, Reuber TL, Frost LN, Feys BJ, Parker JE, et al. Arabidopsis thaliana PAD4 encodes a lipase-like gene that is important for salicylic acid signaling. Proc Natl Acad Sci U S A. 1999;96:13583-8.

Kulich I, Vojtíková Z, Sabol P, Ortmannová J, Neděla V, Tihlaříková E, et al. Exocyst subunit $\mathrm{EXO} 70 \mathrm{H} 4$ has a specific role in callose synthase secretion and silica accumulation. Plant Physiol. 2018;176:2040-51.

Lei J, Finlayson SA, Salzman RA, Shan L, Zhu-Salzman K. BOTRYTIS-INDUCED KINASE1 modulates Arabidopsis resistance to green peach aphids via PHYTOALEXIN DEFICIENT4. Plant Physiol. 2014;165:1657-70.

Livak KJ, Schmittgen TD. Analysis of relative gene expression data using real-time quantitative PCR and the $2^{-\Delta \Delta C T}$ method. Methods. 2001;25:402-8.

Louis J, Gobbato E, Mondal HA, Feys BJ, Parker JE, Shah J. Discrimination of Arabidopsis PAD4 activities in defense against green peach aphid and pathogens. Plant Physiol. 2012;158:1860-72.

Louis J, Leung Q, Pegadaraju V, Reese J, Shah J. PAD4-dependent antibiosis contributes to the ssi2-conferred hyper-resistance to the green peach aphid. Mol Plant-Microbe Interact. 2010;23:618-27.

Ma JF. Silicon transporters in higher plants. In: Jahn TP, Bienert GP, editors. MIPs and their role in the exchange of metalloids. New York: Springer; 2010. p. 99-109.

Ma JF, Tamai K, Yamaji N, Mitani N, Konishi S, Katsuhara M, et al. A silicon transporter in rice. Nature. 2006;440:688.

Menzies J, Bowen P, Ehret D, Glass AD. Foliar applications of potassium silicate reduce severity of powdery mildew on cucumber, muskmelon, and zucchini squash. J Am Soc Hortic Sci. 1992;117:902-5.

Meyer D, Pajonk S, Micali C, O'Connell R, Schulze-Lefert P. Extracellular transport and integration of plant secretory proteins into pathogen-induced cell wall compartments. Plant J. 2009;57:986-99.

Mitani N, Yamaji N, Ago Y, Iwasaki K, Ma JF. Isolation and functional characterization of an influx silicon transporter in two pumpkin cultivars contrasting in silicon accumulation. Plant J. 2011;66:231-40.

Miyake Y, Takahashi E. Effect of silicon on the growth of solution-cultured cucumber plant. Soil Sci Plant Nutr. 1983;29:71-83.
Montpetit J, Vivancos J, Mitani-Ueno N, Yamaji N, Rémus-Borel W, Belzile F, et al. Cloning, functional characterization and heterologous expression of TaLsi1, a wheat silicon transporter gene. Plant Mol Biol. 2012;79:35-46.

Nishimura MT, Stein M, Hou BH, Vogel JP, Edwards H, Somerville SC. Loss of a callose synthase results in salicylic acid-dependent disease resistance. Science. 2003;301:969-72.

Pegadaraju V, Louis J, Singh V, Reese JC, Bautor J, Feys BJ, et al. Phloem-based resistance to green peach aphid is controlled by Arabidopsis PHYTOALEXIN DEFICIENT4 without its signaling partner ENHANCED DISEASE SUSCEPTIBILITY1. Plant J. 2007:52:332-41.

Pieterse CMJ, Leon-Reyes A, Van der Ent S, Van Wees SC. Networking by smallmolecule hormones in plant immunity. Nat Chem Biol. 2009;5:308.

Rafi MM, Epstein E, Falk RH. Silicon deprivation causes physical abnormalities in wheat (Triticum aestivum L). J Plant Physiol. 1997;151:497-501.

Rashid MH, Khan A, Hossain MT, Chung YR. Induction of systemic resistance against aphids by endophytic Bacillus velezensis YC7010 via expressing PHYTOALEXIN DEFICIENT4 in Arabidopsis. Front Plant Sci. 2017:8:211.

Reynolds OL, Keeping MG, Meyer JH. Silicon-augmented resistance of plants to herbivorous insects: a review. Ann Appl Biol. 2009;155:171-86.

Shetty R, Fretté X, Jensen B, Shetty NP, Jensen JD, Jørgensen HJL, et al. Silicon-induced changes in antifungal phenolic acids, flavonoids, and key phenylpropanoid pathway genes during the interaction between miniature roses and the biotrophic pathogen Podosphaera pannosa. Plant Physiol. 2011;157:2194-205.

Shetty R, Jensen B, Shetty NP, Hansen M, Hansen CW, Starkey KR, et al. Silicon induced resistance against powdery mildew of roses caused by Podosphaera pannosa. Plant Pathol. 2012;61:120-31.

Takahashi E, Ma JF, Miyake Y. The possibility of silicon as an essential element for higher plants. Comments Agric Food Chem. 1990;2:99-122.

Thordal-Christensen $\mathrm{H}$, Zhang Z, Wei Y, Collinge DB. Subcellular localization of $\mathrm{H}_{2} \mathrm{O}_{2}$ in plants. $\mathrm{H}_{2} \mathrm{O}_{2}$ accumulation in papillae and hypersensitive response during the barley-powdery mildew interaction. Plant J. 1997;11:1187-94.

Van Bockhaven J, De Vleesschauwer D, Höfte M. Towards establishing broadspectrum disease resistance in plants: silicon leads the way. J Exp Bot. 2012; 64:1281-93.

Van Bockhaven J, Spíchal L, Novák O, Strnad M, Asano T, Kikuchi S, et al. Silicon induces resistance to the brown spot fungus Cochliobolus miyabeanus by preventing the pathogen from hijacking the rice ethylene pathway. New Phytol. 2015;206:761-73.

Vivancos J, Labbé C, Menzies JG, Bélanger RR. Silicon-mediated resistance of Arabidopsis against powdery mildew involves mechanisms other than the salicylic acid (SA)-dependent defence pathway. Mol Plant Pathol. 2015;16:572-82.

Wei Y, Zhang Z, Andersen CH, Schmelzer E, Gregersen PL, Collinge DB, et al. An epidermis/papilla-specific oxalate oxidase-like protein in the defence response of barley attacked by the powdery mildew fungus. Plant Mol Biol. 1998;36:101-12.

Wen Y, Wang W, Feng J, Luo MC, Tsuda K, Katagiri F, et al. Identification and utilization of a sow thistle powdery mildew as a poorly adapted pathogen to dissect post-invasion non-host resistance mechanisms in Arabidopsis. J Exp Bot. 2010;62:2117-29.

Wiese J, Wiese H, Schwartz J, Schubert S. Osmotic stress and silicon act additively in enhancing pathogen resistance in barley against barley powdery mildew. J Plant Nutr Soil Sci. 2005;168:269-74.

Xiao S, Brown S, Patrick E, Brearley C, Turner JG. Enhanced transcription of the Arabidopsis disease resistance genes RPW8. 1 and RPW8. 2 via a salicylic aciddependent amplification circuit is required for hypersensitive cell death. Plant Cell. 2003;15:33-45.

Yang L, Li P, Li F, Ali S, Sun X, Hou M. Silicon amendment to rice plants contributes to reduced feeding in a phloem-sucking insect through modulation of callose deposition. Ecol Evol. 2018;8:631-7.

Ye M, Song Y, Long J, Wang R, Baerson SR, Pan Z, et al. Priming of jasmonatemediated antiherbivore defense responses in rice by silicon. Proc Natl Acad Sci U S A. 2013;110:3631-9.

Yoshida S. Chemical aspects of the role of silicon in physiology of the rice plant. Bull Natl Inst Agric Sci Ser B. 1965;15:1-58.

Zhan $L P$, Peng DL, Wang $X L$, Kong LA, Peng H, Liu SM, et al. Priming effect of root-applied silicon on the enhancement of induced resistance to the rootknot nematode Meloidogyne graminicola in rice. BMC Plant Biol. 2018;18:50.

Zhang Q, Berkey R, Blakeslee JJ, Lin J, Ma X, King H, et al. Arabidopsis phospholipase Da1 and D $\delta$ oppositely modulate EDS1-and SA-independent basal resistance against adapted powdery mildew. J Exp Bot. 2018;69:367588. 